\title{
From critique to utopia
}

This chapter argues that his attachment to the idea of critique inhibits Feenberg from delivering fully on the radical, utopian aims that motivate his theory of technical politics. Feenberg defines critique as a form of thought that is marked by 'persistent reference to nature, reflection and individuality', and which, on this basis, opposes 'the totalitarian power of technology'. He adds that this critique of technology, 'distinguishes critical theory from various forms of postmodernism and post-humanism' (2002: 33). At the same time, however, Feenberg accuses other thinkers in the Marxian tradition of 'trivialising or evading' the question of what the socialist technology of the future might be like, and asserts that this issue must be confronted if critical theory is 'to carry conviction' (2002: 18). He tries to develop a theory, then, that is both true to the definition of critique just cited and delivers on this promise to address the question of the nature of future technology.

As we have seen, the critical theory of technology provides conceptual resources with which to understand aspects of contemporary technology design as a negation or distortion of technology's true potential. Feenberg asserts the necessity of affirming that potential, but the critical nature of the theory means that it can only conceptualise potential negatively, as that which is not currently realised. This antinomy arises out of Feenberg's attempt to combine critique with utopian thinking, or, more precisely, to use critique to achieve utopian ends. Critique entails endless suspicion of the technical (and everything else), while utopianism requires openness to the possibility of fantastic, technologically facilitated modifications of human society and culture. Feenberg has a foot in both camps and consequently, even as he opens the door to utopian thinking, he steps back to a fairly orthodox Marxian position that restricts speculation about future technology, and imposes a check on his own insistence that critical theory must be prepared to say something positive about it, or court bad faith. 
In this chapter, Section 1 returns to Feenberg's account of the 'historical essence' of technology, which is where he repudiates the notion that technology's threat (to culture, to nature) is intrinsic rather than historical. In his alternative, relational definition, technology is found in artefacts and activities distinguished by a characteristic intersection of function and meaning. Here, Feenberg identifies the technical object with the former, referring to this as the 'stripped down' version of artefacts, but emphasises that it only becomes technology proper when it is incorporated into the meaning-making practices he theorises as secondary instrumentalisation.

As we have seen, under capitalism functional objects become technology in a way that is lacking the all-important shell of reconciliation with human meaning. This accounts for the distinctively technological appearance of modern, capitalist society, while disclosing an important sense in which it is actually less technological than other cultures. The latter implication, however, is not elaborated by Feenberg and never becomes a positive principle in his theory. Instead, in the context of reflection on the meaning dimension of technology, function is presented as the truth of an object, and as such it conditions what that object can mean. Because of the negative entanglements of technology with bureaucratic and other forms of power in modern societies, function also tends to be construed negatively, especially by philosophers, as the locus of a fundamental violence done to nature. ${ }^{1}$

There is a version of this argument in Feenberg's theory of primary instrumentalisation. There he asserts that a basic decontextualisation of objects from their place in nature is part of the historical essence of technology. As we saw in the previous chapter, some rival theorists, especially Bruno Latour, have questioned this. In Section 2, attention turns to PeterPaul Verbeek's post-phenomenological critique of Feenberg, in which he suggests that primary instrumentalisation might be better understood in terms of a less controversial notion of patterning, or imposing form on experience, which is then subject to cultural mediation and made meaningful. The benefit of this approach is that it allows a more active role for objects as part of the technological situation, since they participate in shaping the sense they make, so to speak, rather than always being cast as passive or violated. This idea seems to comport well with Feenberg's Marcusean search for a design practice based on harmonies rather than coercion.

However, the danger in Verbeek's position is that the notion of an ethics immanent to technology design becomes entirely relativised to a context that is understood in post-human terms. The threat here is that ethics are actually made subordinate to a techno-aesthetic principle with no discernible role for meta-level scrutiny of design choices. 
Feenberg's attachment to some notion of directionality in social and historical processes serves as a counterweight to this. Section 3 discusses his use of Gilbert Simondon's idea of concretisation as a way to contain the relativism with respect to outcomes that haunts constructivism, without lapsing into Marxian technical determinism.

Section 4 suggests that Feenberg's attempt to steady the ship in this way reflects a one-sidedness in his theory, according to which the discursive and the political are always both subordinate to the technical (which carries the historical process forward through concretisation) and superordinate to it (politics redeems technology development after the fact and provides ideas that determine its meaning). The focus of technical politics is, then, the discursive mediations applied to technology rather than its substantive dimension. In his presentation of technical politics Feenberg is limited by his attachment to critique to offering a politics of technology, neglecting the utopian question of a positive technicisation of politics. He locates the operations of oppositional and dissenting agents with an interest in technology in discourse, rather than in technical practice itself. This imbalance in his theory precludes the utopian operation of advancing technical solutions to human, social and cultural problems. In this respect, his attachment to critique means that he is behind concrete developments in contemporary technical politics, where activists now develop software that changes the material realities of social and political struggle, while discourse plays a secondary role in mediating their activity.

In technical politics, as Feenberg theorises it, discourse outside technology is the source of ideas but is always obliged to follow behind technology development. This is the traditional position of critique, as negatively portrayed by Latour - it is condemned to turn up after the fact and explain why things turned out badly. In Section 5, I suggest that, in order to deliver on his utopian promise, Feenberg needs to include space for progressive substantive bias in technology design and positively identify willed technical transformation as the privileged vehicle of socialist transition. If technical politics is to be more than just a category-mistake, in which technology is judged by criteria that were developed for something else, then it also needs to include reflection on the technicisation of heretofore political questions. According to this argument, technology designs inform the value basis of the socialist model, rather than merely bearing their impress. Any vision of socialism worth its salt must include employments of technology that shape human subjectivity and rules of co-existence to create new forms of social life. Since power here operates below the level of discursivity, or deliberation on meanings, the Marxian or critical formula of democratised technology design is insufficient. 


\section{Historical essence}

Feenberg rejects essentialist definitions of technology that construe it as inherently menacing to human values, arguing instead that technical advance is itself a human value. At the same time, he rejects the kind of determinism which maintains that culture is in the position of 'keeping up' with technical development and embracing the potential it presents. His alternative involves recognising the pervasive entwinement of technology development with questions of meaning and value, but also the ways in which that entwinement gets obscured beneath one of its effects, namely the prevailing perception of what technology is. Here reification - the abstraction of technology from the real social and historical processes that constitute it - enters the philosophical definition of technology. What makes Feenberg's theory a critical theory is his conviction that the task of unmasking abstraction and breaking down reification, while informed by philosophy, is also a vital moment in the creation of a different kind of technics.

He works here from within a Marxist problematic, which is concerned with the historical abstraction of human properties. Human action makes history and drives the development of human productive power, including technology. But in the course of that process, human powers become abstracted, or alienated, and appear as special properties of dominant social classes, or 'reified' entities, like the market (often credited with the rapid wealth creation of the last two and a half centuries) or technology itself (often viewed as something that acts on history from outside). Critical theory understands itself as charged with the task of dissolving these illusions to reveal the human, social processes that underlie them, and, at the same time, unmasking the operations of power that make them seem autonomous of those processes. Critique is a way of thinking that removes false appearances, and in Marx's version it is allied to emancipatory social activism and politics. Critique confirms its truth by becoming active in the situations it describes, bringing people of like mind together and empowering them not only to see through dominant illusions but also to forge new social realities grounded in co-operation that prefigure a society free from alienation and reification.

As we saw in Chapter 1, Feenberg sets himself the challenge of developing a theory that includes technology among the concerns of critique and incorporates an account of technical transformation into critical theory's ideas about agency or praxis. In this way he hopes, by way of the theory of 'democratic rationalisation', to reconstruct the idea of progress. In this version of critical theory, technology, bureaucracy and other edifices of modern society are to be taken back, as it were, by the human beings who created them and 'recoded', so that they can be set to more benign purposes. 
To this end, Feenberg advances a non-reified, properly historical definition of the essence of technology, in the following terms:

I will define the essence of technology as the systematic locus for the sociocultural variables that actually diversify its historical realizations. On these terms, the essence of technology is not simply those few distinguishing features shared by all types of technical practice. Those constant determinations are merely abstractions from the socially concrete stages of a process of development. It is the logic of that process which will now play the role of the essence of technology. (2001: 201)

The 'logic' Feenberg favours is the combination of two aspects of technological development that must be present in any society whatsoever, which he calls primary and secondary instrumentalisation. As we saw in Chapter 4, 'Primary instrumentalization [PI] characterises technical relations in every society, although its emphasis, range of application and significance varies greatly' (Feenberg 2001: 202). PI (sometimes referred to as functionalisation) has four elements, which Feenberg describes as 'four reifying moments of technical practice' (2001: 203):

1. Decontextualisation, in which objects are abstracted or separated from their natural contexts. Feenberg also refers to 'isolating' them and, notably, to their 'reifying extraction' (2002:179). The latter seems strange, because it means that any and all technology has a 'reifying' moment. In reification, what is true is transformed into a falsehood, and what is false is also a kind of concealed truth. Reality is present in a reified entity but in deceitful guise. It seems as if Feenberg is saying that when natural objects are abstracted in this way it involves seeing them more clearly but from a perspective that is somehow false or inauthentic.

2. Reductionism, in which objects are assessed for their promotion of affordances, or in relation to a programme of purposes. This places technology firmly within the problematics of presentation and representation. Reduction re-presents what is given in nature with a focus on useful properties, and Feenberg equates the qualities of the object that get excluded or put into the background by this process with objective 'potential' (2001: 204).

Feenberg emphasises that 1 and 2 are objectifying moments of PI and adds two more features of the process, which he says are moments of 'subjectivation' (2001: 208):

3. Autonomisation, which means that once isolated and related to purpose, the object confers a new freedom on the subject, namely to act in a given domain without consequences, or with protection from the feedback that such action normally triggers. This is a feature of most tools. 
4. Positioning, which refers to understanding and using the laws of nature to gain strategic mastery in a given context.

The relational definition of technology locates it at the intersection of PI with secondary instrumentalisation (SI). In other words, there may, in principle at least, be instances of reifying practice, reduction to function, autonomisation and positioning that are not technological. Only when conjoined to SI would they be part of the process that Feenberg says constitutes technology. SI (which he sometimes refers to as 'realisation' or 'concretisation') involves:

1. Systematisation, in which objects are integrated into networks of people and other objects: long tightly linked networks in modern societies, shorter and with looser connections in traditional ones.

2. Mediation, which involves ornamentisation or decoration and the application of symbols conferring meaning: a common practice in relation to pre-modern tools, less so in the case of industrial machinery.

These are aspects of the objective life of technological artefacts, while the second two moments of SI concern their relation to human users.

3. Vocation, which refers to the emergence of a group of people who develop an affinity with the new technology in processes through which the tool 'produces' its user.

4. Initiative, which is the opening up of a margin of manoeuvre for users, in which they can experiment with uses of the technological object. This is important to the tactical dimension of technical politics.

By focusing his definition on the intersection of PI and SI, Feenberg inserts a sociological dimension into the philosophical definition of technology. Here, 'the underdetermination of technological development leaves room for social interests and values' (2001: 205). Technology emerges where it is socially shaped and 'insure[s] congruence between technology and society' (2001: 205). Feenberg describes how, in this process, technology often initially destabilises, then comes to work with and re-enforce, established social arrangements, including those based on power.

Instrumentalisation theory is a quasi-transcendental, pragmatic theory of technology as a social process. PI and SI stipulate core features of that process that Feenberg considers must be present for a thing or situation to count as technology. He elaborates on them with reference to other theories of technology. Of PI, for example, he says that its first two moments correspond to Heidegger's account of technology as 'enframing', while the third and fourth he compares to Habermas's characterisation of money and power as social steering media, which are present in most human societies. However, both of these theories 
famously oppose technology to the communicative, cultural dimension of human experience. Indeed, Feenberg accuses Habermas of trying to get 'a whole social critique' out of this by opposing the system to the cultural lifeworld while overlooking their embodiment 'in technical devices and disciplines that include [both and] much else besides' (2001: 203). Feenberg's own theory preserves the opposition of technical-instrumental and communicative reason, with the difference that he locates it within technology.

In this way Feenberg's definition introjects meta-level reflection and reflexivity into technology. Definitions, including Habermas's, that cast technology as outside of the scope of cultural, meaning-making processes are themselves a uniquely modern version of this kind of theoretical reflection. They comport with the notion of the detached expert who comes at social situations from outside, with manipulative intent and little or no regard for the human consequences of their actions. In Habermas's theory this occurs because, as part of the systems sphere, technology is ruled by an action orientation that eschews time-consuming deliberation and is thoroughly guided by technical imperatives (Habermas 1985: 202). In contrast, from Feenberg's perspective the understanding of technologists and technical action reflects the influence of reification. While Feenberg sometimes characterises technical action in similar terms to Habermas, his explanation of its character is different. In short, it is not true that technologists in modern society have no idea of what they are doing in a meta-sense - only that, having internalised these discourses, they tend not to see that having such an idea is important to what they do when they are doing it.

Feenberg interprets this situation politically and identifies it as the reification of technology in hegemonic technological rationality, which he counterposes to technical activism. He presents instrumentalisation theory as superior to other philosophical definitions of technology because they invoke ahistorical abstractions (instrumentalism, enframing) from the reality of technology, which is better understood as socially contested and thoroughly political. The introjection of these latter elements into the very meaning of technology is a welcome theoretical advance. However, in defining technology as the 'logic of a process', it is questionable whether Feenberg really proffers a definition that is less guilty of abstraction than other theories.

His analysis of technology as a process concentrates on the historically contingent and contested character of efficiency and draws out the purported play of this and associated concepts in determining the meaning of technology. By contrast, in Marx's work the 'systematic locus' of technical activity is empirical; it involves the historical interface of labour, knowledge and the productive forces. Feenberg's account, specifically in the theory of PI, includes a historically continuous, even incorrigible 
element of reification, which is confusing because elsewhere in the theory he emphasises that reification is a feature specific to modern, rationalised societies. If PI includes reification then modern technology involves a reified or reifying perspective on an activity that already reifies part of the world. This doubling of reification is unsettling and strikes one as symptomatic of a problem in the theory.

Feenberg's argument is that people's encounters with technology differ from their experiences with other (natural) objects because 'an initial abstraction is built into our immediate perception of technologies' (2001: 211). As we've just seen, with technical objects a 'primary function' is foregrounded and defines the interaction, and this 'seems to set us on the path towards an understanding of technology as such' (2001: 211). Even as people encounter a technical object for the first time, they experience an unusual mediation in which linguistic and aestheticsensory interpretative moves and accommodations are punctured or disrupted by a prior objective structure that inflects the reading of this particular class of things. The seed of reification is present in PI and cultivated by modern technology's SI, and this explains the persistent self-evidence of technology in its reified form, as authoritative, rational, efficient, etc.

In the theory of PI, Feenberg characterises this objective structure in terms that are openly derived from substantivist and essentialist philosophies. In his effort to get a sociological component into the philosophical definition of technology, he includes negative associations of technology - such as enframing, or reducing worldly interactions to instrumental purposes - while separating them from the philosophical positions that gave rise to them. His idea is that these negative characterisations have traction because they correspond to a basic level of experience or common sense, rather than as special insights of the late Heidegger. It makes sense, therefore, to recast them as historical contingencies. Feenberg makes an important contrast with traditional societies, where, he writes, 'the functional point of view ... co-exist[s] peacefully with other points of view ... none of which are essentialised' (2001: 211).

Feenberg's hermeneutics of technology, then, insists that social and cultural meanings are always integral to technology: there is no unmediated experience of technology. This point has critical import because it makes it clear that technology cannot be properly understood without acknowledging that it always combines function with some kind of meaning that makes it comprehensible to human beings, who interpret the world from a particular embodied and cultural standpoint. At the same time, the PI is intended to do justice to the fact that the element of function continues to be definitive for technology, without being its essential determinate. The narrowed definition of technology 
in terms of mere function, which Feenberg says predominates in capitalist modernity, is a reification because it is a socially induced distortion of technology's truth, caused by the pre-eminence of professional, technical disciplines ${ }^{2}$ and their implication in social domination. Feenberg writes that '[a]s the prestige of these disciplines spreads, their approach to technology becomes the model for common sense and philosophy alike' (2001: 212) - that is, it is hegemonic.

Identifying technology with its function is, in Feenberg's terms, a kind of abstraction, a reification. This dimension (functionality) is not simply wrapped in signs that tell putative users what the artefact can do. It is as social-relational as any other aspect of technology: '[a]s mere physical objects abstracted from all relations, artefacts have no function and hence no properly technological character at all' (2001: 213). There is a problem for this position, however, which arises out of the argument made in the last chapter about the changed aesthetics of technology. The character of the technical inflection, or the way in which the technical object intrudes (obtrudes) on sense- or meaning-making activities seems to have shifted even in the years since Feenberg first made this accommodation with his substantivist precursors in the philosophy of technology. In particular, the notion that when encountering a technical object one is guided or steered by a reified function, and that this defines the interaction as coldly instrumental or spiritually empty, jars with the experience that most people have of contemporary, especially digital, technologies. In other words, it is no longer common sense. The relationship people have with their smartphones, activity trackers or other digital gadgets of everyday life does not match the description this seems to imply of them, as reified and authoritative.

\section{Hermeneutics and the object}

Post-phenomenology considers Feenberg 'humanist' because he only treats of technology as it is constructed or discursively mediated. PeterPaul Verbeek, for example, agrees with Feenberg that there is no transcendental meaning of technology (instrumental efficiency gains, narrowed worldview, etc.) that underpins (or overrides) socially constructed ones (Verbeek 2013). He proposes to approach technology at the level of individual artefacts rather than viewing them all as the expression of a way of thinking or as occupying a particular predetermined place in our social imaginary (Verbeek 2006: 196). Technologies are as they manifest in context and not instances of a universal class sharing common properties, or dependent social variables subject to the rule of their human designers. They are entwined with other situated elements and agentic, so that the question of their identity is dynamic and open, as it is for 
all social actors. Technologies are always both emergent in this sense and irreducible to other levels of description, including the idioms of explanatory physical science that might be expected to account for their behaviour in advance.

While Feenberg's instrumentalisation theory is not essentialist, or even substantivist in the accepted sense of that term, it does stipulate, in a pragmatic invocation of the idea of function, what historical technical artefacts are - what makes them all technology. This definitional move is refused by Verbeek. Instead, he proposes that technology has the constant feature that it 'gives form to human existence' (2006: 48) and 'imposes form' on our experience of the world (2006: 209). In this sense, it plays a role in shaping human existence but one that operates outside of linguistic mediation and symbolic meaning. Crucially, moreover, the form it confers is not specifiable in advance or deducible from essentialist premises or historical constants, including reification. From this perspective, all of the moments in Feenberg's instrumentalisation theory are only contingencies, features of a historically specific experience of technology. Technology produces a 'pattern' (2006: 180) in human existence, but which pattern it produces varies between instances.

Like Feenberg, Verbeek postulates two layers to the technical artefact - one embodied, shaping form and conferring pattern, the other involving symbolic appearance, meanings and discourse. For him, each artefactual encounter involves the becoming of things and people, shaping a world that appears a certain way to humans. Verbeek's thesis is post-phenomenological because of the active role he assigns to objects as agents in the process of their own production: they exist in a sense that goes beyond (and conditions) their appearance to and meaning for human beings. He calls for a design culture that anticipates the moral consequences of artefacts' agency, as part of the process of their production. Rather than deferring normative or moral questions to the abstract consideration of their likely impact on social contexts, he regards norms as immanent to the design process, and assigns ethical weight to the artefacts themselves as part of this. For this reason, Verbeek writes of the intrinsic desirability of transparent designs (2006: 228) that would enable users to see the full workings of a given device, rather than more simplified interfaces tailored to meet requirements anticipated by designers, which then become prescriptive and limit in advance what artefacts may say or do.

This sounds similar to technical politics, in that Verbeek places ethics as internal to the technology design process, but, unlike Feenberg, he does not understand this in terms of opposed instrumentalisations (PI/ $\mathrm{SI}) .^{3}$ For Verbeek, Feenberg's technical politics is restrictively humanist because, although he locates democratic potential within technology's 
developmental trajectory, he identifies the source of progressive ideas as outside of it in the realm of public political discourse. ${ }^{4}$ Describing the historical process in which technology has been shaped by capitalism, Feenberg observes that the exclusion of values from the technical sphere sees them resurface outside it, so that ' $\mathrm{t}$ ] he very same process in which capitalists and technocrats were freed to make technical decisions without regard for the needs of workers and communities generated a wealth of new "values," ethical demands forced to seek voice discursively' (2002: 22). Technical politics, then, involves the importation of these discursively formulated values into the technical sphere as currently constituted. It is in light of this that Feenberg argues that one of the goals of the critical theory of technology is 'to account for the increasing weight of public actors in technological development' (2002: 24).

Elsewhere, when he discusses the example of changes to computing in the 1980s, Feenberg describes matters differently. There he identifies progressive elements within the technical professions as Foucauldian 'specific intellectuals' (2002: 100). Efforts to make computers into communication tools rather than sources of top-down management control, he says, were brought about by 'specific intellectuals act[ing] in the margin of maneuver associated with a technical domain in order to transform the code establishing that domain' (2002: 101). The two accounts are not contradictory, and in practice Feenberg wants us to believe that both things are true: non-technical publics lobby for change and progressive members of technical professions can act with similar values in mind, or even be influenced by putative users.

The ambiguity over whether this occurs from the outside, as action upon the code to change it, or as a mutation from within the code itself matters, though, because it suggests a one-sidedness in the critical theory that is not present in Verbeek's argument. Technical politics is concerned with values formulated outside of the technical sphere - communication, education, democracy, the aesthetics of usability and so on - and the progressive nature of some intra-technical action is identified as such only in so far as it appears to comport with those values. Yet this neglects what is specifically technological about technology, and what it might do to enhance politics and alter prevailing social and cultural values. Instead, we are told that 'everywhere technology goes, centralised hierarchical social structures follow' (2002: 24), which preordains the failure of technical politics. Feenberg writes as if the technological aspect of technology, which in the dystopian technological imaginary has always been on the side of power, can take care of itself and needs no protection or advocacy from philosophy. For Verbeek, in contrast, design is not the domain of codes that provide openings for extraneous norms, because norms are already immanent to it and the ethical character of 
technology development is not an 'after the fact' assessment controlled by the (mournful) wisdom of hindsight.

Consequently, Verbeek points out, it is precisely the failure to recognise that things have a moral valence that gives rise to technocracy' (2006: 216). This point is very close to Feenberg's suggestion that capitalist formal bias involves not a socially induced distortion of the technical object so much as a failure to control or contain it in a SI. But comparing the two views reveals the limits set by Feenberg's attachment to critique. Verbeek's point is that there seems to be no reason in principle why a failure of SI, of the kind that is central to Feenberg's diagnosis of modernity, might not result in spectacularly benign or beautiful devices unencumbered by the impress of extraneous political or ethical valuations. The difference here is subtle but important because Feenberg's quasitranscendental characterisation, while cautiously formulated, appear to be basically concerned to combat a technology historically associated with power, rather than to positively affirm its capacity to substantively alter social reality.

Instrumentalisation theory draws too much on a hermeneutics of suspicion applied to technology to be able to facilitate the conceptual pivoting that Feenberg requires from his theory. To move from critique of technology to utopian projection concerning its role in a more benign future, its ambivalence needs to be cancelled and its transformative power affirmed. The idea of function is less useful here than the notion of form, invoked by Verbeek in the comments just cited. The abstraction and isolation of technical elements described in instrumentalisation theory can be retained, but describing these as drawing out function already presupposes an understanding of the way that technology is integrated with social purposes - in other words, it strays into describing the capitalist SI. ${ }^{5}$ In contrast, the idea of PI as the imposition of form that conditions meaning helps to clarify the idea of a 'systematic locus' that defines the historical essence of technology.

However, a problem remains with Verbeek's position, namely that it involves a post-modern relativism about values in technology that Feenberg rightly wants to avoid. While he feigns to disavow such relativism, Verbeek acknowledges that his theory is 'motivated by the postmodern aversion to context-independent truths' (2006: 115). If all the relevant values and norms are immanent to the technology situation and, importantly, there is no way to specify what technology ought to be for that is not some kind of 'humanist' imposition, then it seems that anything might go. Feenberg attempts to reconstruct the notion of technological progress in order to establish and clarify a sense of the overall direction or purpose against which technology development ought to be assessed. 


\section{Concretisation, subjectivation and the technological monad}

When Feenberg defines technology in terms of its social logic, he invokes a specific entwinement of the dimensions of function and meaning, which he clarifies with reference to Gilbert Simondon's idea of concretisation. In this concept notions of form and function are, helpfully, combined. Simondon distinguishes 'technicity' in artefacts from their usefulness, arguing that it is characteristic of technical systems that their structures felicitously incorporate uses and relations to the environment, in a process of 'elegant condensation' based on 'the discovery of synergies between the functions technologies serve and between technologies and their environments' (Feenberg 2001: 217).

Feenberg takes over this account of technology's tendency to expand and to incorporate new purposes as it unfolds, and argues that its logic is progressive. He writes that ' $\mathrm{t}$ ] he process of concretisation has a progressive character: design can be ordered in a sequence going from the most abstract to the most concrete' (2001: 217). Since new knowledge is manifest in new technical structures, technology development combines cognitive advance with social and cultural development. Finding purposes that technology can fulfil is part of a 'reflexive accommodation' to the new capacities that technology presents as it differentiates itself. This progressive movement includes enhanced economic efficiency but, potentially at least, other things as well.

Feenberg attempts to adapt Simondon's perspective by opening it up to constructivism, arguing that 'functions', in Simondon's sense, 'gather social groups' (2001: 218), and in this way technology forms a 'systematic locus for the sociocultural variables that ... diversify its historical realizations' (2001: 218). However, this marriage of Simondon and constructivism is, at best, problematic. Constructivism's social processes select from technological properties that are inherently contingent, even haphazard, in their development, because they are technically underdetermined. Moreover, and especially in Feenberg's version, these processes involve social struggle and antagonism, and their outcomes are strongly contingent on how those political contests are resolved. In contrast, Simondon's theory of concretisation follows a very different logic, which he likens to the process of crystal formation out of a chemical milieu. There is a clear discrepancy between the proposition that technological designs tend to acquire functions as they unfold in accordance with such a strong sense of pattern and the argument that they are shaped by social and political struggles.

Feenberg acknowledges that constructivism is 'obviously incompatible with Simondon's tendency to determinism' (in de Vries 2015: 3), but tries to create a synthesis based on 'ambiguities' in Simondon's presentation of his theory. He recognises the scale of the challenge, 
acknowledging that while constructivism excludes any idea of abstract or autonomous technicity, Simondon's theory appears to allow no role for social shaping in the genesis of technologies. Feenberg's synthesis involves assimilating formal technicity to generalities of social theory, especially the idea of rationalisation. He writes that 'ever since Marx and Weber, the mainstream social critique of modernity has emphasised technification, the cultural generalisation of what can loosely be called technicity' (de Vries 2015: 3), a move that aligns Simondon's concept to the idea of societal rationalisation. It is difficult not to consider this rather forced, however. There is, it seems to me, an affinity between the idea of technicity and Verbeek's notion of form, but it is tendentious to attempt to align these ideas with anything like societal rationalisation.

In Feenberg's hands, then, Simondon's concept of concretisation is primarily normative - that is, it describes the logic of technology development as it ought to be (2001:219-220), if its potential were not thwarted by modern society. Simondon rejects the application of 'external' criteria of quality, including profit and utility, to technical artefacts. The idea of concretisation emphasises that the becoming of technologies involves movement from abstraction in design towards what he calls the 'superabundance' of acquired functions, in excess of anything that might have been anticipated at the outset:

Concretisation brings not only new properties, but complementary functions, beyond those sought after, which we might call 'superabundant functions.'... These properties of the object surpass expectations; it is a partial truth to say that an invention's purpose is to attain an objective, to produce an entirely predictable effect. An invention is brought into being in response to a problem, but its effects extend beyond the resolution of the problem, due to the superabundant efficacy of the created object when it is a true invention. (Cited in Chabot 2013:15)

Simondon's concept has utopian implications, since it implies a progressive logic of technology development involving the open-ended accrual of functions to technical elements. This logic combines social and technical factors, and it suggests a polyvalent, rather than ambivalent, account of technology's relationship to social change. Simondon does not sharpen the opposition of concretisation to capitalist distortion in the way that Feenberg does - he describes how particular points in capitalist mining operations become lively centres of innovation (Chabot 2013: 13), for example, rather than decrying capitalism's distorting effects.

Feenberg identifies concretisation as setting out a 'path to wider inclusion through redesign' (2017: 181), and his proposal is to use this concept to outline a suitably 'complex trajectory of progress' (2001: 218). But the alliance with Simondon is not without its challenges. For example, a 
discrepancy is apparent when Feenberg writes of 'strategies of concretisation, which aligns it not with tactics and the perspective of grass roots technology activists but rather with the 'positioning' moment of PI, in which technology is articulated to the interests of power working through a depleted SI. The fact that societal rationalisation (or differentiation), stripping down, and so on, run into the future, while, on his reading, concretisation repeatedly brings value questions back in, leads Feenberg to call concretisation the 'technological unconscious' (2001: 220) of modernity. At this point, concretisation becomes the intuitive foundation of critique; a reminder of harmony and integration as lost features of our relation with the natural world, rather than a method of utopian futureprojection. The 'technological unconscious' pulls us back to the truth of a more integrated technological trajectory but, as such, it is a kind of repressed memory that surfaces in the wake of technical advance, to call for the reassertion of imperilled human values.

As we have seen, Feenberg refers to neglected potential in modern technology caused by its shaping by capitalist purposes. He argues that an alternative civilisation might recover what he calls 'traditional technical values' (especially vocation and self-realisation through tool use), or it could produce its own version of SI, invoking new values and strengthening concretisation. In this way, technical politics combines the 'themes of substantivist critique' with opposition to capitalism. ${ }^{6}$ Simondon's theory can help with this if it is articulated to more futurefacing parts of Feenberg's theory.

One of the challenges faced by critical theory of technology is the absence of a thoroughly immanent standard of evaluation for technical design practice - a standard of the kind that Verbeek seems to be after. Feenberg's attempt to grasp the 'historical essence' of technology provides resources with which to think that issue through, not least because it was developed in part to counter post-modern and relativist arguments. The difficulty is that if technology is only as constructed, or as it emerges in the technological situation as described by post-phenomenology, then there is no way to place its development in relation to wider questions of social advance or progress. ${ }^{7}$ Verbeek's immanent ethic of the technological object is, in this sense, insufficiently robust because it doesn't facilitate the evaluation of technologies against the wider backdrop of questions of civilisational value or historical directionality. Simondon's ideas of technicity and concretisation can help with this, since they present an idea of the relational essence of technology (its form, as against the more sociological 'function') and a theory of the logic of its unfettered development, which is both aesthetic and normative.

These ideas might facilitate an alternative theorisation that accounts for the way in which changes at the level of ontology (alterations to capabilities and affordance in the world) are stitched into 
ontic meaning-making processes wherein people gain familiarity with techniques and operate with them from day to day. As we saw in the last chapter, this is the goal that Feenberg sets for theory in his idea of a re-aestheticisation of technology. The underlying difficulty is to reconcile the fact that some descriptions of technology seem to grasp its more fundamental aspects with the equally true proposition that 'an adequate definition of real technology, as opposed to the narrow, idealised crosssection studied by engineering involves much besides the formal-rational properties of devices' (2001: 216). That is, there can be social disputes and contests over design in which critical theory can take an interest, but some perspectives on the technical object yield more truth about it than others - which is problematic because these are the ones most likely to be monopolised by expert groups aligned with power. Feenberg's suggestion is that technology's truth can be a distinctive marriage of formal function and human interests, of the kind we find in medicine and sedimented in the vocational practice of doctors, engineers and others who are technologists, and who faithfully create themselves as subjects through the technical encounter that defines them and their tools. Feenberg's notion of a technical subjectivation provides the framework within which to think this technical-political relation.

The theory of SI places technology in the problematic of representation central to Adorno's conception of critical theory. Adorno's version of critique seeks to loosen the hold of established epistemic models by showing that each identity has a 'natural history' (Hullot-Kentor 2006) involving an excess that is both essential and excluded. One of the aims of this approach is that of allowing objects to speak, which is achieved by highlighting the resistances concealed within any act of naming. This can be illustrated with reference to cultural practices like music, which, at its most 'stripped down', is just noise that can be heard by humans but which becomes something more than that when its bare mechanism is incorporated into culture. Experiences of the new within music (or art generally, and perhaps also technology) raise the question of what is included in the definition, and by emphasising this as a point of methodological principle, Adornian analysis generates glimpses of music as such as it passes between moments of relative fixity and those in which the raw material escapes the nomological net. Moments like that of the captivating movement of a mechanism detached from any function or purpose are indicative of how this argument, developed in connection with art, might apply to technology. ${ }^{8}$

Adorno writes of a 'shudder'9 produced by some artworks, when the subject temporarily loses the conviction of self-identity and is open to the truth of its ontological precarity. The pervasive uncertainty concerning what counts as real on either side of this encounter gives rise to a subjective sense of one's self as merely a passing and barely distinct 
representation: 'The I is seized by the unmetaphorical semblance-seeking consciousness that it itself is not ultimate but semblance' (2002: 246). Now, the shudder is a moment in the mediation of form as the objective within the subject. Adorno compares the role of critique here to that of psychoanalysis in relation to dreams or other psychological symptoms (2002: 137). Only critique is able to distinguish the presence of form, which serves as a kind of curative insight, much as psychoanalysis helps a neurotic to identify the real source of their suffering and thereby liberates them from intrusive or compulsive thoughts. Critique leads the subject to move with the resistant or oppositional content of the artwork itself as it refuses the dominant ordering of reality. Critique here creates a back channel between the inner content of artworks (their form) and the unconstrained freedom of thought that would be an emancipated subject - Adorno refers to 'logic without conclusion' (2002: 137) - that is implied in the critically mediated encounter with authentic artworks.

In artistic subjectivation the experience of form implies a change of constellation, a new reality in which subject and object are reconfigured and towards which true or authentic thought is inclined. Adorno's theory is Marxist in the sense that it retains belief in both a form of subjectivity worthy of a better life and a historical truth adequate to it. In aesthetic experience they are both contained within what he calls the 'aesthetic monad' (2002:123) to indicate how this relation is abstracted from social and historical reality, mirroring it in a way that resists and repudiates it. In the changed techno-social configuration that is digital culture, it makes sense to adapt this line of thought to develop Feenberg's notion of a technological subjectivation. The role of critique is to bring the technological unconscious to consciousness in connection with specific concretisations. Its truth, like that of art, is the promise of a better world that cannot be represented directly. Faithful to this, the technologist's action is always a procedure that both explores (differentiates) and concretises. Fidelity to technological truths becomes, then, the effort to delineate a new world within the old.

Technological subjectivation differs from that of art, however, in that rather than opening a back channel to history it almost invariably involves a play for future significance. ${ }^{10}$ Rather than rejecting technical reason as intrinsically instrumental and in need of compensation or correction, it should be understood as necessitating precisely the kind of openness to the object that is invoked in Adorno's theory. Invention is a process that involves an intuition of the ways in which materials behave; whether this involves an appreciation of mechanism and movement or of the intrinsic elegance of lines and blocks of code, all true invention has an aesthetic dimension. Technical subjectivation involves the kind of profound questioning that Adorno associates with the aesthetic, in which one's own identity is at stake. This much seems to be entailed in 
Feenberg's reference to technology as a subjectivation: through it, individuals become something substantively different than they were before. An encounter with the technological event and the decision to embrace a particular meaning subjectivates its human participants at the same time as it allows objects to say something new. It is also, of necessity, a political development because it simultaneously involves a wider claim to relevance, as a vision of future society. Whenever a technological subjectivation occurs it implies an (often very radical) agenda for social change.

Feenberg's version of this process involves vocation: a calling to work in an area that is often the basis of specialisation and expertise. There is a strong resonance between this calling to and love of technology and Adorno's analysis of the transformative potential of the artwork. A subject of technology is one who knows its potential from the inside, so to speak: who embodies the mesh of technical and human in its experimental phase. Their being rests on a decision or decisions about new technical capabilities, which they select and attach themselves to. This is a twoway process in which the loosening of prior subjective identifications ${ }^{11}$ creates a space in which objects can speak and act.

There is a connection here with Verbeek's thesis that the technological artefact is an ethical agent in excess of the descriptions applied to it by technologists. The latter's post-modernism amounts to the idea that adopting an inclusive approach to artefacts as agents can be understood as ethical practice, without postulating any connection to wider narratives, in particular to any idea of progress. This is unsatisfactory because normative claims of the kind that are important to technical politics must submit themselves to the judgement of the historical process as movement towards greater human self-realisation. The cultural condition of post-modernity highlights the lack of any political bridge from localised concern with ethics in design to history as arbiter in this sense, since there are apparently no historical narratives within which the ethics of increased sensitivity to objects acquires socio-historical significance. Here, Simondon's idea of concretisation provides a starting point, since it entails a reconfiguration of subject and object that will be an enhancement of both.

\section{The reification of critique}

The idea of technical politics was to some extent conceived in response to a situation in which increasing numbers of people started to demand an active role for themselves in technical decisions that affected their lives or concerned them. As seen above, Feenberg emphasises that the interventionist consciousness required for technical politics is an extra-technical 
mediation. He argues that those who are excluded from decision-making 'have recourse to discourse' (2002: 153), where they can discuss technology and formulate their own demands. However, if technicisation is stripped of its associations with the negative formulations in the theory of PI, then the question of the technicisation of politics and culture is a positive, potentially optimistic one. The fact that Feenberg never asks it is the legacy of a critical theory that thinks of itself as the locus of a special kind of rationality that is opposed to instrumental reason. Attachment to this figure of thought prevents Feenberg from fulfilling one of his own strictures on what a critical theory must do. Critique prevents us from thinking through the transformation of technology, technical infrastructure and technical practices as part of the transition to a new civilisation, and from thinking technically about that transition.

Epistemically, critique first defined itself as defence of a non-technical way of understanding the world ${ }^{12}$ Its fundamental task is to distinguish dimensions of human culture that should not be subject to scientific analysis and routinised through the application of technical 'solutions'. Feenberg's attachment to critique is therefore in tension with his goal of progressive rationalisation implemented through democratised technology design. In his theory, even though technology and rationalisation are now held to be open to alternative configurations, it seems that they are still to be comprehended from within a framework that is inherently suspicious of them. But if alternative, democratic or subversive rationalisations are possible then there is reason to expect that technical designs inspired by them might be compatible with, for example, family meals and the management of interpersonal relationships. ${ }^{13}$

A basic principle of technical politics is Feenberg's argument that ethics applies to technology design. This leads him to approve of some tendencies within technology design over others, so that he writes, for example, that 'any technology that enhances human contact has democratic potentialities' (2002: 91). However, the normative foundations for this judgement are never clarified, and this creates the impression that they are not immanent principles but seem to be brought to the technology situation from outside. The obvious source for Feenberg's choice of communication as the core value is Habermas, who identifies agreement and consensus as conditions of possibility of linguistic communication and, for that reason, serviceable as the basis for an immanent ethic of non-systematised social situations. However, Feenberg rejects Habermas's opposition of communication to the systems sphere, because it makes technology amoral and places it beyond the reach of democratic control. If he is unable to endorse communicative ethics because it excludes technology and technical action in principle, it is difficult to see how Feenberg reaches his own prescription for good technology design as intrinsically favouring communication. The question begged by this 
move is whether a technology might be deleterious to human connectedness, perhaps fostering more privacy or enabling people to avoid one another, yet still be good technology.

Here, as elsewhere, Feenberg endorses the sentiments but not the thinking behind an essentialist criticism of technology and its erosion of culture. The problem is that these sentiments are not in themselves uncontroversial and, separated from the arguments that gave rise to them, they appear as personal preferences. Politically, critique conceives itself as involved in the defence of democratic politics, as the domain of free, undistorted communication against the incursions of 'the system' (including technology). Feenberg's attachment to this opposition, notwithstanding his attempt to install it internally to technology, prevents him from developing a theory of willed technological transformation, which is a necessary point of departure for utopian thought.

The theory of technical politics opens up technology and technical reason to discussions about values and politically motivated transformations, but, as we have seen, the model for reform is always a matter of impressing values onto technology; it never concerns the technical transformation of social or political practices and values. Defining the core of technology in terms of PI, Feenberg locates interventions and struggles over meaning only at the level of SI, where technological forms are socially mediated. In other words, what is at stake in technical politics is the meaning of technology, rather than its form or what it does in a substantive, physical or material sense. ${ }^{14}$

In consequence, technical politics as Feenberg conceives it involves an imposition of politics (its values, ends and rationality) onto technology. But if it is not to be based on a category-mistake, in which technology is simply judged by criteria that were really developed for something else, then technical politics also needs to include space for the technicisation of heretofore political questions. The idea of technical politics needs to be rebalanced to reflect the fact that, as Verbeek points out, technologies bring their own arguments to bear upon issues of normative import. In a fully developed dialectic of technical politics, technology should be part of politics; and technical values, once they are drawn out through liberated technical practice, should be inscribed in political solutions and cultural innovations.

Activists are already creating technologies that propound alternative values as a matter of their substance rather than shaping technology in line with ideals and values (like communication) derived from discourse. An example of this is the 'Universal Automation' browser extension software created by hackers in the UK in 2013, in response to the government's 'Universal Jobmatch' programme. ${ }^{15}$ Universal Jobmatch was a job search website for unemployed workers which enabled the Department for Work and Pensions to monitor benefit claimants' job-seeking activities. People 
who failed to apply for enough jobs would be subject to reductions in benefit, or 'sanctions.' Under the slogan 'Workers of the world ... Relax!', Universal Automation software automated the job application process, enabling benefit claimants to circumvent the regime by applying for hundreds of jobs in a few seconds. ${ }^{16}$

In Feenberg's terms, the Universal Automation program is an example of progressive substantive bias (a category he rejects - see Chapter 2 above), since it has no other use than supporting unemployed workers in their struggle to live free from state harassment. The concept of technical politics needs to be rebalanced to reflect this kind of development in which, just as technology is opened up to receive values, social and political goals are formulated and implemented in and through technical action. Although it is only a piece of software, Universal Automation is a more articulate statement of the right to social security than any number of blog posts, magazine articles or books of critical theory. To comprehend and move with this kind of development, critique needs to shed its own self-identity, its image of itself as something that is not technical. When critique stops reifying itself it will be able to identify positively with thought that is active in the world, and attach itself to objects that actively shape the future.

\section{Technologically authorised socialism}

As we have seen, through his idea of the technical code Feenberg has demonstrated that technology is open to multiple articulations and identified this as an opportunity for progressive politics. In this sense, his work marks an important advance over previous Marxian scholarship, when he writes that:

Scientific-technical rationality is not an ahistorical monolith that must be defended or rejected as a whole but an evolving complex of attributes that can be configured in a variety of ways with diverse social implications. Alternative rationalisations depend on which among these attributes is emphasised. (2002: 131)

Technical politics is the field of struggle opened up by this insight. The competing social agents described by constructivism, who seek to impress different meanings onto artefacts in the development process, are now understood as the bearers of values related to political perspectives. Successful 'rationalisations' alter the significance of technology and its place in society and, potentially at least, correspond to a wider process of democratisation. Feenberg draws technology into politics and makes it possible to envisage a different kind of technological civilisation. 
The ultimate aim of technical politics is to trigger a global transformation affecting what technology means. Feenberg writes of a series of 'mutually supporting transformations' (2002: 27), leading to a superior civilisational model. His vision of technical politics can be represented as a series of oppositions:

Technical rationality
Hierarchy
Brutalist aesthetic
Managerial control
Neutrality

\author{
Communication \\ Democracy \\ Naturalist aesthetic \\ Social connection \\ Ethics
}

Capitalist modernity favours the tendencies in the first list but leaves a series of openings through which people can push for items in the second. Ultimately, this kind of grass roots activity will tip the whole meaning of technology over into something compatible with human self-realisation and not subordinate to the demands of the capitalist social system.

Feenberg argues that technology should subserve the societal goal of widening democracy, and that enhanced democratic control over technology design is the way to achieve this. His model of socialist transition retains Marx's emphasis on the contradiction that capitalism engenders between the need for skilled, knowledgeable workers to operate sophisticated machinery on one side and the requirement that they serve as docile, unquestioning subordinates on the other. As workers become more educated, so they are more likely to perceive the iniquities and inefficiencies of capitalism and to use their expertise to change the situation (1991: 30). Feenberg argues that this contradiction is manifest today and is part of the explanation for the growing interest in technology design. Even if, most of the time, squabbles over the meaning of a technology are mundane reflections of sectional interests with no obvious bearing on larger questions, it remains the case that a great deal is decided ... by the shape of our tools' (2002: 19). Feenberg maintains that 'the very definition of modern life is up for grabs' (2002: 120) in disputes over technology design.

Verbeek's post-modernist version of technical politics maintains that we can benefit from the critique of this or that individual technology indeed, that such critique is part of what technology design involves but that there is no wider historical eschatology that helps to orient these decisions. This is unsatisfactory because it relativises the ethical dimension of technology design and defers the larger questions persistently raised by technology development. We can summarise this by saying that Verbeek wants to let objects speak but has no deep interest in what they have to say. Embracing concretisation as a utopian moment involves working with the open-ended advance of technological form 
as it meshes with the human material of history. Within this, technological events are not straightforwardly deterministic but are mediated through subjectivations founded on human decisions, and utopian politics affirms those decisions when they are guided by the conscious belief that a better future is possible - that is, they correspond to the immanent ethics of technology design.

Feenberg rightly challenges those who seek a quicker, more direct route to a superior civilisation to explain how such a transition will be possible without social action aimed at challenging the technical division of labour - that is, the deep entanglement of technology with expertise and hierarchy-reproducing knowledge practices. However, the one-sided nature of his theory reveals itself here: Feenberg's assumption is that the goal is democratic technology, whereas from the standpoint of technological subjectivation a superior civilisation primarily requires better technology. This is a matter not so much of bringing technology under political control as of allowing technologies political speaking rights. Just as art establishes an inner connection between a non-identical subject and a more authentic future, so technology too can inspire the conviction that a new world is possible: indeed, this is the benign promise of all technology before it gets thoroughly entangled with capitalist and other societal logics. More than that, it can begin to implement that conviction as part of a pre-configurative utopian strategy.

Rather than bearing the impress of particular, contingent values, better technology would have implications for the meaning of those values in practice, including democracy. What that technology consists in, its fundamental orientation, can itself be a focus for political will-formation. Technology design can be politicised by raising value questions within its design, and, as Feenberg points out, there is evidence that changes like this have already happened to design culture. However, seeking better technology as part of a superior society is not only a matter of imagining a world where workers can determine what technology is from day to day (the grass roots conception of technical-political freedom); it also involves imagining a world in which technology acts on people to produce new dispositions, habits of mind - in short, different kinds of sociality.

I submit that a rebalanced technical politics should take seriously the polyvalent, multi-dimensional, immanent logic of technology itself and incorporate the possibilities it presents into theoretical reflection on the future. This properly expands on the utopian moment implicit in the notion of new concretisations, by establishing conceptual space for a willed transformation of technical infrastructure. It involves acknowledging technological subjectivation as a moment in technical practice that is fundamentally autonomous of political considerations but invariably consequential for society and politics. Thinking this through 
requires that we accept the technicisation of politics as the dialectical corollary of the politicisation of technology.

As the later Foucault showed, the modern subject is a product of structured predispositions that are often technically implanted. Other experiential forms of subjectivity will be selected and foregrounded by different technical apparatus in the future. In recent decades the internalisation of work discipline and performative norms by a 'streamlined subject' have been facilitated by technologies that produce individuals who justify themselves and their actions in terms of efficiency and rational self-interest, not because they have deliberated or reflected on these values but because they were sedimented in the socio-technical environment. For the most part, social media notwithstanding, civic responsibilities have not been part of this reprogramming of the self.

In the age of social media it is anachronistic to pretend that questions of privacy, meaning, the nature of love and so on may not be susceptible to technical 'solutions'. A rebalanced technical politics could focus on substantive alterations to existing social media technologies, with the goal of inclining human behaviour in specific, desired directions. The values of any new society will be played out in a change of fundamental attitudes on the part of citizens, and there is no reason to expect them to do this on their own. Instead, new concretisations of subject and object can be envisaged that incline people to be socially responsible citizens, that promote and support acts of solidarity and kindness, personal traits of courtesy, good manners and tact. Social credit systems which track peoples' behaviour and reward them for good conduct, stimulating a more co-operative disposition, have alarmed some left-liberal commentators (Greenfield 2018), but working with the form of technology to bring about substantive social change almost certainly means being prepared to countenance similar projects, in which technology changes the meaning of ideas like freedom and democracy.

\section{Notes}

1 This is what leads Feenberg's critics to discern an ambivalence in his work on the issue of essentialism - see earlier discussions. In this chapter I am suggesting that the real issue is his attachment to critique.

2 These disciplines embody a refined understanding of function, detached from considerations of meaning; hence, in the terms mooted above they contain truth but in a false perspective.

3 Similarly, Douglas Kellner argues that since aesthetics and function are 'equiprimordial', there is no reason for Feenberg to hypostatise their separation, or to refer to the resulting theory as 'instrumentalisation' theory (Arnold and Michel 2017: 278). 
4. It is worth noting that this is the condition of application for Feenberg's own work, or of its link to praxis. Critical theory, it seems, cannot be parsed into technical manuals or engineering textbooks.

5 As when Feenberg writes that 'The concept of function strips technology bare of values and social contexts, focusing engineers and managers on just what they need to know to do their job' (2001: 213).

6 Feenberg writes that this is the 'heady air we must breathe if we want to make a fundamental difference to the shape of technical advance' (2001: 224).

7 Indeed, there seems to be no non-culture-specific way to identify it as technology.

8 An illustration of this idea of form which can pass between functional settings, acquiring different meanings when it gets re-embedded in a new context of use, is provided by mechanical alphabets created in the century before the development of industry in Europe. These proto-machines were wooden models, whose 'functions' are obscure or non-existent, but which each instantiate a principle of mechanism (Snickars 2017). The science of mechanism was dubbed 'kinematics' by German engineer Franz Reuleaux, himself a source for Marx's study of capitalist machinery (Frison 1988: 303). It has since declined as a branch of engineering (Moon 2003).

9 'True, the annihilation of the I in the face of art is to be taken no more literally than is art ... aesthetic experiences are as such psychologically real, it would be impossible to understand them if they were simply part and parcel of the illusions of art. Experiences are not "as if". The disappearance of the I in the moment of the shudder is not real; but delirium, which has a similar aspect, is nevertheless incompatible with artistic experience. For a few moments the I becomes aware, in real terms, of the possibility of letting self-preservation fall away, though it does not actually succeed in realizing this possibility' (Adorno 2002: 245).

10 It is plausible to construe this activity as involving a 'technological monad', since in opening up and re-forming their identities on the basis of their technical activity, technological subjects also become independent reflections of the whole of social reality. Here, though, the relation is not past-oriented and critical but rests on a utopian decision about the future.

11 This relates to changes in habitus associated with technology use, such as learning to use a computer mouse when previously one had only ever used pen and paper. Such changes have implications for the symbolic mediation of personal identity - see Kirkpatrick (2015) for discussion of this in connection with computer gaming.

12 The defensive function of critique has a lineage stretching back to Kant, whose 1781 Critique of Pure Reason (1992) initiated the modern critical tradition by demonstrating the limits of scientific deduction as a method for addressing questions of a metaphysical nature. Kant placed his faith in a reason opposed to technical artifice when he argued that 'Men will of their own accord gradually work their way out of barbarism so long as artificial means are not deliberately adopted to keep them in' (1992: 59).

13 Feenberg argues that 'the substitution of "fast food" for the traditional family dinner can serve as a humble illustration of the unintended cultural consequences of technology' (2002: 7). 
14 There is an interesting irony here in that while Srnicek and Williams (2017) and contemporary accelerationists are willing to imagine substantively different technologies, like spaceships for interstellar travel, they have nothing more than wishing to offer in relation to its reform, while Feenberg offers rich accounts of how technology has been shaped but only ever concerns himself with changes to its meaning, fighting shy of utopian recommendations concerning the technology of the future.

15 The software can be downloaded from: www.automation.strikenow.org.uk.

16 It seems to me that Universal Automation is not merely 'socially shaped' as part of a contest over meanings, but is better understood as technology that deliberately favours some ways of living, and even some people's interests, over others. Viewed in this way, it is less an intervention than an experiment in the development of infrastructure for a future society. To deliver on its utopian aspiration, the theory of technical politics needs to include the possibility of technology like this that is substantively biased by (progressive) design and has the capacity to force a new situation, every bit as much as the production-line imposed capitalist labour conditions onto generations of workers. The model here is not discursive but authoritative, even coercive, and the relevant value is not democracy but equality. 